\title{
Psychosocial benefits of a mentoring program for youth-headed households in Rwanda
}

\author{
Lisanne Brown \\ Janet C. Rice \\ Neil W. Boris \\ Tonya R. Thurman \\ Leslie M. Snider
}

See next page for additional authors

Follow this and additional works at: https://knowledgecommons.popcouncil.org/departments_sbsr-hiv

Part of the Demography, Population, and Ecology Commons, Family, Life Course, and Society

Commons, International Public Health Commons, and the Medicine and Health Commons

How does access to this work benefit you? Let us know!

\section{Recommended Citation}

Brown, Lisanne, Janet C. Rice, Neil W. Boris, Tonya R. Thurman, Leslie M. Snider, Joseph Ntaganira, Laetitia N. Nyirazinyoye, Edward Kalisa, and Emmanuel Nshizirungu. 2007. "Psychosocial benefits of a mentoring program for youth-headed households in Rwanda," Horizons Research Summary. Washington, DC: Population Council. 


\section{Authors}

Lisanne Brown, Janet C. Rice, Neil W. Boris, Tonya R. Thurman, Leslie M. Snider, Joseph Ntaganira, Laetitia N. Nyirazinyoye, Edward Kalisa, and Emmanuel Nshizirungu 


\section{Psychosocial Benefits of a MENTORING Program For \\ YOUTH-HEADED HOUSEHOLdS IN RWANDA}

A quasi-experimental study showed that mentoring from adults can measurably mitigate adverse psychosocial outcomes among youth heads of households. The mentorship program is a scaleable approach to improving psychosocial wellbeing among vulnerable youth.

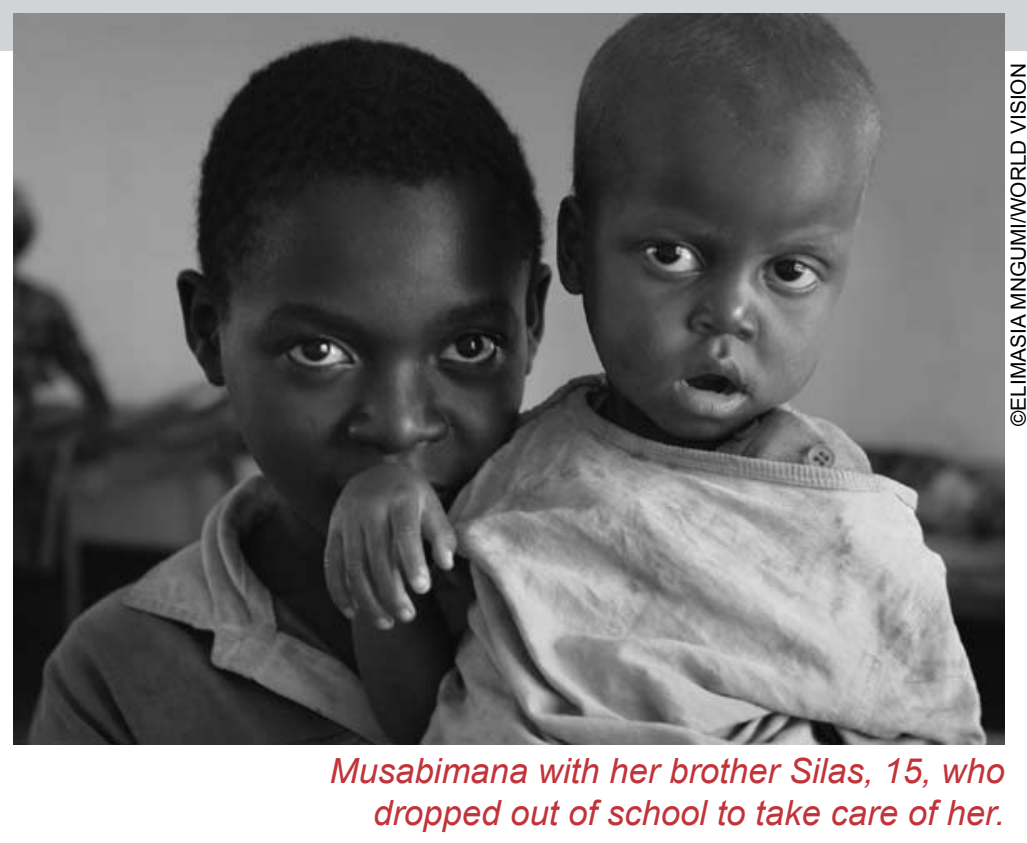

The AIDS pandemic has caused unprecedented suffering and social disruption for children and communities throughout sub-Saharan Africa. Children and youth affected by AIDS suffer the loss of adults and with them the protective structures for their growth and development. In Rwanda, the combined effects of the 1994 genocide and the AIDS pandemic have devastated the lives of children and families. Estimates from 2006 indicate that 16 percent of children under age 18 in Rwanda have lost one or both parents (UNICEF 2006). There are more than 65,000 households headed by youth living without adult care and supervision. More than 300,000 young people living in these households have been "left behind," not only by parents and other caregivers who have died, but also by extended families and communities who stigmatize and fail to support them (Rakita 2003).

The phenomenon of youth-headed households in the region is a relatively recent development, precipitated by the effects of the AIDS pandemic at the household and community levels, as well as broader shifts in cultural values, family structures, and the global socioeconomic environment (Preble 1990; Hunter 2000). Despite the long history of fostering in sub-Saharan Africa, family and community safety nets are overstretched. Youth-headed households may be a legitimate coping strategy; for instance, some children and youth may feel that

To read more about this study, go to www.popcouncil.org/horizons/projects/Rwanda_PsychOVC.htm 
staying together within their household and protecting their land and property is the best option for their survival and future.

However, children living in youthheaded households are less likely to attend school, have greater vulnerability to physical and mental health problems, and may demonstrate behavioral problems (due to a lack of appropriate adult guidance and comfort) and potentially hampered development (Evans 2005). Without a caring adult to advocate for their interests, they are also more vulnerable to physical and sexual abuse, property and land grabbing, and labor exploitation (Hunter 2000).

A critical factor affecting the health and well-being of children in youth-headed households is their ability to access and mobilize positive social support as a buffer to various threats (Snider and Dawes 2006). Although extended family members are a potential source of support, they are unfortunately at times also the perpetrators of abuse, exploitation, and property grabbing following the parents' death (Foster et al. 1995). One study in Rwanda revealed that orphans consider relatives to be more exploitive than strangers, and orphans listed relatives as their least important source of social support (Rakita 2003). Whether from family or unrelated community members, social exclusion and marginalization of orphans and other vulnerable children are critical mediators of a wide range of psychosocial problems for orphans and, ultimately, their ability to survive and thrive (Snider and Dawes 2006).

\section{Intervention Model}

This study tested a model of adult mentorship and support to improve psychosocial outcomes among youth-headed households. After a thorough screening process, World Vision Rwanda (WVR) trained 156 adults (60 percent male, 40 percent female) as volunteer mentors. Through regular home visits, these mentors developed a stable, caring relationship with children and youth in their local community living without an adult caregiver. The mentors monitored the well-being of vulnerable children and youth; gave them love, attention, and encouragement; provided guidance and support; transferred life skills; and helped ensure their health and safety. This intervention model was intended to strengthen the supportive environment for children's healthy growth and development, and mitigate the psychological impacts of disrupted caregiving structures.

\section{Study Setting}

The study was conducted in southwestern Rwanda in a rural province, one of the poorest regions in the country. In collaboration with community leaders, WVR identified 990 youth-headed households living within this area in 2001 and began to provide these households with a basic needs program, including assistance with housing, education, health, and food.

\section{Study Design and Methods}

The study used a quasi-experimental design to assess the impact of the adult mentoring program on the psychosocial well-being of youth living without adult care. Youth-headed households in two of the four districts in the province-Karaba and Nyamagabe-received the mentoring program in addition to the basic needs program during the study period. Youth-headed households in the other two districts-Mudosomwa and Nyraguru — served as the comparison group. The basic needs program continued in all of the districts throughout the study, and the mentoring intervention was rolled out in the comparison districts after completion of the follow-up survey.

The research team collected two rounds of cross-sectional survey data from youth who served as heads of their households. The baseline survey was conducted in March 2004 (Brown et al. 2005) and the followup survey was carried out two years later in March 2006. All youth-headed households served by the WVR basic needs project in the four districts were approached to participate in the study. The youth heads of each household who could be located and who gave informed consent $(n=832)$ were interviewed in their 
homes by a trained interviewer. Only those aged 24 and under at baseline $(\mathrm{n}=692)$ and 26 and under at follow up ( $n=593)$ were included in the analysis. The research team also obtained qualitative data through focus groups with youth, adult mentors, and community members at both baseline and follow up; selected quotes at follow up are presented.

The survey instrument was designed by the study team in close collaboration with a local technical committee of youth and professionals to ensure its cultural and conceptual appropriateness. The instrument was further refined through pretesting and piloting. It was administered in Kinyarwanda, the predominant language in the study area.

The questionnaire was designed to measure the impact of the mentoring program on the well-being of the youth household head and other children living in the household. In addition to directly exploring experiences with the mentoring program, the questionnaire covered a wide range of topics, including the physical and psychological health of household members, household support and social connectedness, knowledge about HIV, and exposure to abuse and other risks. Interviews lasted one to two hours depending on the size of the household.

Analysis was conducted using STATA (version 8). Analyses explored linkages between exposure to the intervention and five key psychosocial outcomes: 1) perceptions of adult support, 2) marginalization, 3) grief, 4) maltreatment, and 5) symptoms of depression. Initial analyses assessed whether one group changed more than the other over time. If a difference was found, regression analyses were conducted to assess whether the difference persisted after controlling for the following background variables: age, sex, living alone, parent killed in the genocide, highest grade completed, health status, assets index, and number of meals eaten per day.

\section{Ethical Procedures}

Tulane University Health Sciences Institutional Review Board and the Rwanda Ethical Review Board reviewed and approved the study and its instruments. Because youth heads of household in Rwanda are considered emancipated under Rwandan law, youth were granted the right to consent to study participation. During the individual consent procedures, participants were informed orally that the survey involved sensitive questions, that their participation was voluntary, that they had the right to withdraw from the study at any time without penalty, and that World Vision support would be provided whether or not they agreed to participate in the research. Bearing in mind the demands on the time of the youth who serve as heads of households, a small token of appreciation of staple food and other items (i.e., soap, rice, candles) was given to participants, though they were not made aware of this until after the interview.

Interviewers were in a unique and responsible position hearing about participants' difficult experiences and feelings. To prepare them for this role, training included sensitization activities and discussions concerning vulnerable youth as well as interviewing techniques specific to children. Furthermore, they were trained to recognize child participants in need of immediate higher-level interventions and, where appropriate, referral provisions were put in place. If, during the course of the research, youth reported attempting suicide, being abused, or experiencing serious shelter or health needs, referrals were made to WVR for assistance and ongoing support. To aid WVR in provision of adequate support for the most severely affected youth, the study team mapped available mental health resources during the pilot phase of the project.

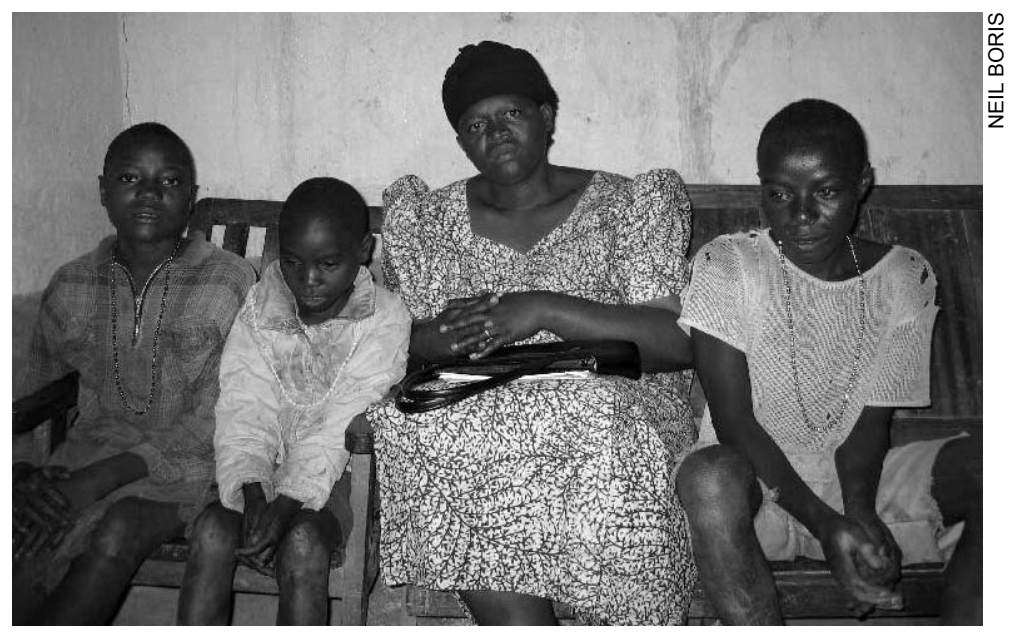

Gaudiose Niyirema, a WVR facilitator, visits a youth-headed household to arrange a basic needs package and mentor visits. 
Youth and community members contributed meaningfully to the development of the program and evaluation instruments. Youth, community members, and other local experts were involved in the review and design of the questionnaire and participated in the technical committee and focus groups. The insights gleaned through these activities ensured that the mentor training, materials, and indicators of program success were relevant to the local context.

\section{Demographic and Psychosocial Characteristics of the Sample}

The baseline sample included 692 youth heads of household who were between the ages of 12 and 24 years. The follow-up sample included 593 youth heads of household, who were between the ages of 14 and 26. It is notable that among all youth participating at baseline (mean age approximately 20 years), over 60 percent reported having served as the head of their household for four or more years.

The vast majority of youth heads of household reported that one or both of their parents was dead; 91 percent reported that their mother was dead, 75 percent reported that their father was dead, and a total of 70 percent reported that both parents were dead. Of those who had lost both parents, just over 40 percent reported losing both parents to illness or from "poison," commonly thought to refer to AIDS. Seven percent of respondents reported losing both parents in the genocide-in the war itself or shortly after the war.

While the overall study sample was comparable on selected demographic characteristics at baseline and follow up, Table 1 reveals that the comparison and in-

Table 1 Equivalence of intervention and comparison groups at baseline

\begin{tabular}{|c|c|c|}
\hline $\begin{array}{l}\text { Background characteristics of youth heads of } \\
\text { household }\end{array}$ & $\begin{array}{l}\text { Comparison } \\
(n=345)\end{array}$ & $\begin{array}{l}\text { Intervention } \\
(\mathrm{n}=347)\end{array}$ \\
\hline Mean age (range) $)^{\star * *}$ & $19.7(12-24)$ & $20.6(14-27)$ \\
\hline Female (\%) & 47 & 46 \\
\hline Live alone (\%) & 22 & 17 \\
\hline Parent killed in genocide* $(\%)$ & 21 & 27 \\
\hline \multicolumn{3}{|l|}{ Highest grade completed* $(\%)$} \\
\hline$\leq 3$ years primary & 50 & 41 \\
\hline$>3$ years primary & 50 & 59 \\
\hline \multicolumn{3}{|l|}{ Health status (\%) } \\
\hline Excellent or good & 25 & 18 \\
\hline Fair & 54 & 59 \\
\hline Poor & 21 & 22 \\
\hline Eat only one meal per day (\%) & 41 & 46 \\
\hline Assets (mean score, range $0-6$ ) ${ }^{\star * *}$ & 3.3 & 3.8 \\
\hline World Vision basic needs (mean score, range $0-6)^{*}$ & 3.7 & 4.0 \\
\hline Adult support ${ }^{* * *}$ (mean score, range $\left.1-5\right)$ & 3.6 & 3.2 \\
\hline Depression ${ }^{* *}$ (mean score, range 1-50) & 23.3 & 25.4 \\
\hline Grief** (mean score, range $1-5)^{*}$ & 3.1 & 3.3 \\
\hline Marginalization $^{* * *}$ (mean score, range 1-5) & 3.1 & 3.4 \\
\hline Maltreatment $^{\star *}$ (mean score, range 1-9) & 1.8 & 2.1 \\
\hline
\end{tabular}

${ }^{*} p<.05 ;{ }^{* *} p<.01 ;{ }^{* * *} p<.001$ 
tervention groups were not equivalent at baseline with respect to key background and outcome variables: youth household heads in the intervention group were significantly older (20.6 years vs. 19.7 years, $\mathrm{p}<$ 0.001 ) and significantly worse off than the comparison group on many characteristics, including having had a parent killed in the genocide, less adult support, higher levels of lifetime maltreatment, and poorer psychological health. However, the intervention group had significantly higher levels of education than the comparison group and reported significantly higher asset ownership. These differences were controlled for in the regression analysis.

\section{Key Findings}

\section{Youth beads of housebolds who participated in the mentorship program perceived a significant increase in adult support.}

Adult support was measured by a 4-item scale (alpha $=.85)$ that asked whether the youth knew and trusted an adult: 1) to offer advice and guidance, 2) to assist in going to the authorities for help if necessary, 3) to provide comfort at times of sadness or sickness, and 4) to always be dependable. The range of possible scores is 1-5; a higher score indicates greater adult support.

During the study period, youth who participated in the intervention perceived a significant increase in available adult support whereas the comparison group perceived a slight (non-significant) decrease (see Figure 1).

I had problems to the extent that I was soon dropping-out of school. But after getting a mentor, he helped and showed me how necessary school is. Today I pass my exams and have a hope that soon I will finish school and get a job.

Female, 20 years old

Evidence of an intervention effect persisted after controlling for important background variables. A strong impact on perceptions of adult support was expected given that the intervention provided a new adult figure in the children's lives. In addition to intervention exposure, higher levels of adult support were associated with living alone, not having a parent killed in the genocide, good health, having assets, and eating more than one meal a day.

\section{Intervention participants reported a signif- cant decrease in feelings of marginalization.}

Marginalization was measured by a 6-item scale (alpha $=.77$ ) that explored perceptions of isolation and stigma from the surrounding community (e.g., the degree to which youth feel people speak badly about them

Figure 1 Changes in mean scores on the adult support scale by study group

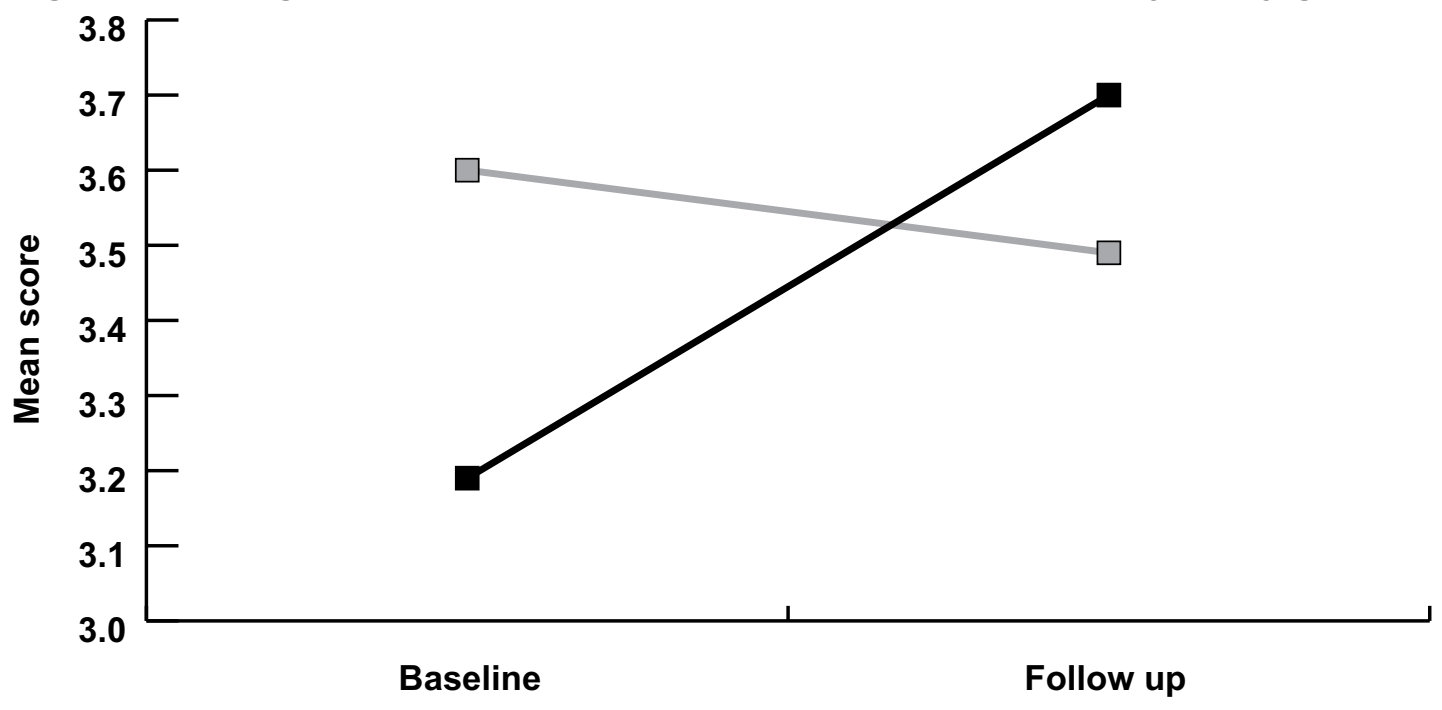

Intervention Comparison 
or feel rejected by others in the community). The range of possible scores is 1-5; a higher score indicates greater marginalization.

Over the course of the study, youth participating in the mentorship program reported lower levels of marginalization at follow up compared to baseline (mean scores 3.35 vs. $3.16 ; \mathrm{p}=.004$ ), whereas there was no change among the comparison group (mean scores 3.13 vs. $3.17 ; \mathrm{p}=.57)$.

After controlling for background variables, an intervention effect was still evident. Advocacy by mentors on behalf of youth may have served to encourage their social integration and acceptance among the larger community. In addition to demonstrating an intervention effect, analyses revealed that living alone, having a parent killed in the genocide, poor health status, not having assets, and having only one meal per day were all factors associated with high levels of marginalization.

I took the time to go to the neighbors to ask them to stop chasing them. Now they give them a place in their parties or other events to the point where the youth can now lend or borrow money from them. The neighbors gave them their trust and the children also don't resent them anymore.

Mentor
Youth who did not participate in the intervention reported a significant increase in feelings of grief.

Grief was measured by a 6-item scale (alpha $=.66)$ that explored youth's reactions to the deaths of their loved ones, including how often they thought about the death and whether they felt anger, had lost faith, or felt life had become meaningless. The range of possible scores is 1-5; a higher score indicates greater levels of grief.

Mentors are there for us. We don't feel lonely anymore and we feel like normal children.

Male, 20 years old

Youth in the comparison group reported experiencing significantly higher levels of grief at follow up than baseline, even after controlling for background variables. Although levels of grief were higher at baseline in the intervention group, there was no significant change at follow up (see Figure 2). These results suggest that the mentoring program may have mitigated a worsening of grief symptoms. The provision of a "parent figure" may have accounted for the stabilization of grief symptoms. High levels of grief at follow-up were associated with having a parent killed in the genocide, poor health status, and having only one meal per day.

Figure 2 Changes in mean scores on the grief scale by study group

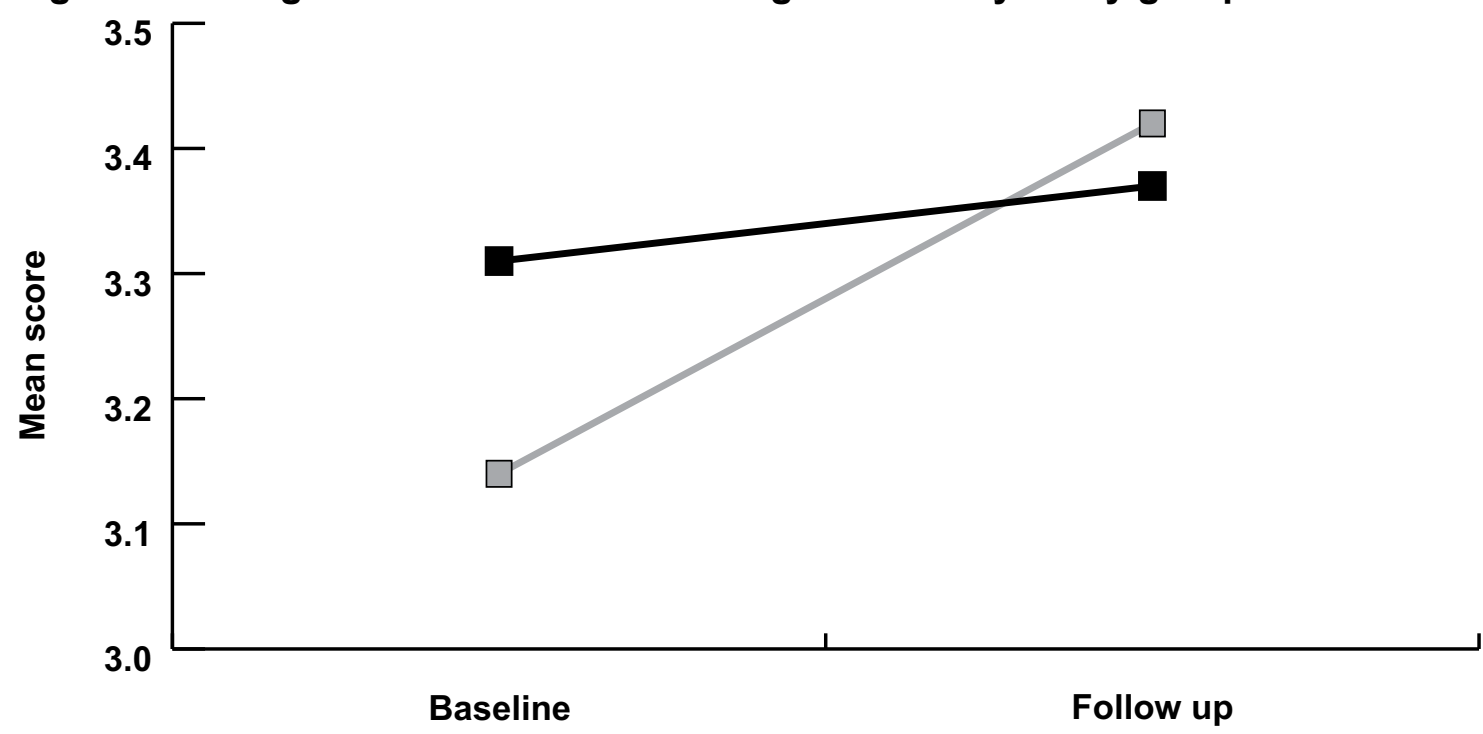

Intervention Comparison 


\section{Youth who participated in the intervention reported a significant decrease in maltreat- ment.}

Maltreatment was measured by a 9-item index that examined experiences of sexual abuse, exploitation, and theft; higher scores reflect more experiences of maltreatment.

The intervention group had a higher mean score on the maltreatment index than the comparison group at baseline (2.13 vs. 1.76); however, this was reversed at follow up (1.79 vs. 1.96).

People used to look at us and disrespect us. But since the mentors come people see that we are watched for and when someone violates our rights he is pursued.

Female, 24 years old

Members of our family used to take our estate from us, but the mentors spoke for us and they gave it back.

Female, 21 years old

Even after controlling for background variables, the comparison group reported experiencing significantly more maltreatment than the intervention group at fol- low up. The presence of an adult visiting the home as well as the initiative of mentors to protect youth may have helped to prevent abuse. In addition to being exposed to the mentorship program, factors associated with reporting maltreatment at follow up included being female, being older, having a parent killed in the genocide, poor health status, and having only one meal per day.

\section{Intervention participants reported a signifi- cant decrease in depressive symptoms.}

Symptoms of depression were measured by using the complete 20-item scale of the Centers for Epidemiologic Studies Depression Scale (alpha $=.86$ ) (Radloff 1977). The range of possible scores is 1-50; a higher score indicates greater depressive symptoms. It is particularly notable that the mean score on the depression scale was very high in both groups. In fact, applying a commonly used, conservative cut-off score of 24 , about half of the study population met the criteria for clinical depression at baseline ${ }^{1}$.

Youth participating in the intervention reported significantly lower levels of depression at follow up compared to baseline (mean scores 23.46 vs. 25.40; $\mathrm{p}=.009$ ), whereas there was no change in the comparison group (see Figure 3). Even after controlling for background variables, there was evidence of an

Figure 3 Changes in mean scores on the Centers for Epidemiologic Studies Depression Scale by study group

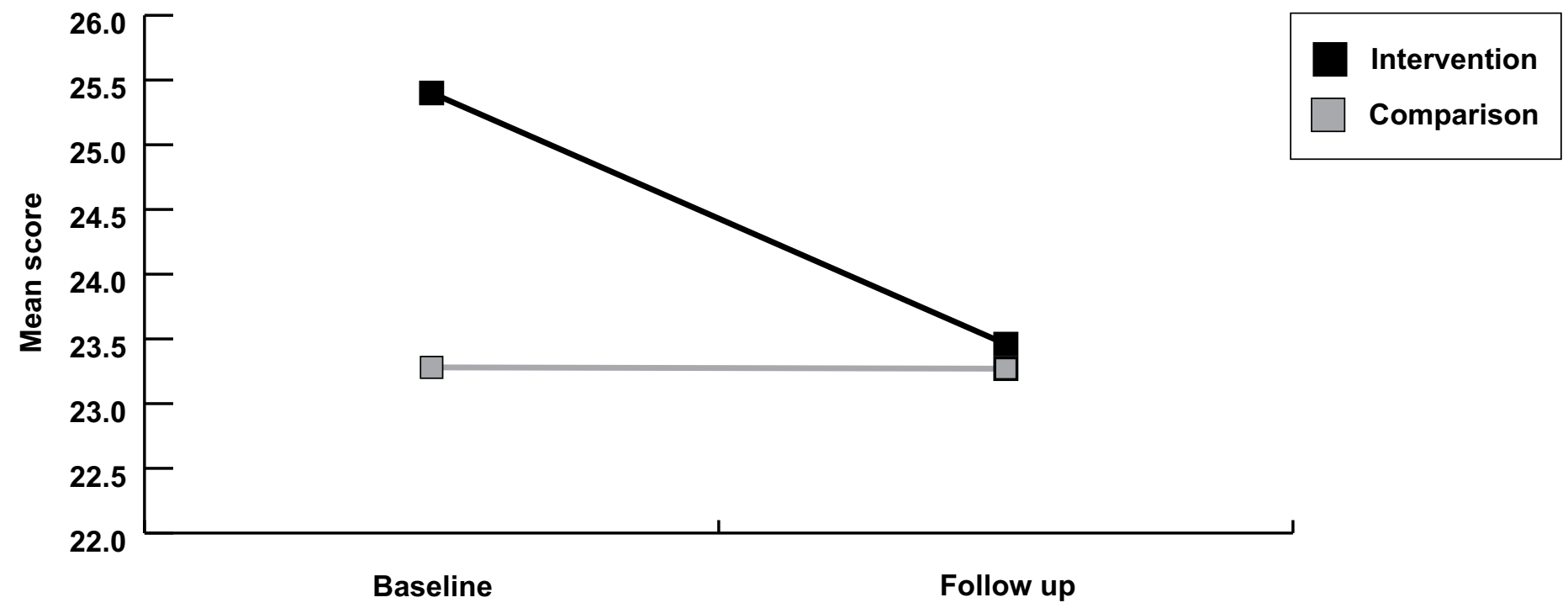


intervention effect. However, it is notable that the effect, though significant, was relatively small. Depressive symptoms, especially high levels of symptoms, are typically persistent. It is particularly impressive that the mentoring program was associated with any measurable decrease in depressive symptoms among affected youth. The results point to the power of a caring relationship in improving severe psychological problems in the absence of clinical interventions. In addition to being exposed to the mentorship program, factors associated with high depression scores include being female, a high level of education, living with others, having a parent killed in the genocide, poor health, having fewer assets, and eating only one meal per day.

\section{A higher frequency of mentor visits was asso- ciated with more positive perceptions of the mentor-youth relationship.}

The research team hypothesized that the more often mentors visited the household, the more favorable youth would perceive certain dimensions of the youth-mentor relationship. When asked about the frequency of mentor visits at follow up, 49 percent of the 296 respondents reported being visited at least weekly, while 35 percent indicated that visits had been once or twice a month, and 16 percent said that visits from their mentor had occurred less than once a month or never.

Youth in the intervention areas were also asked to rate their experience with their mentors on a series of items. Principal factor analysis was used to develop scales representing three dimensions of the mentoryouth relationship:

1. Positive aspects of the mentor-youth relationship (seven items): explored the extent to which youth felt the mentor understood their feelings, their level of trust in the mentor, and the degree to which they felt the mentor gave them good advice (alpha $=.88)$.

2. Time spent together (four items): assessed youth's perceptions about the adequacy of the frequency and duration of mentor home visits (alpha $=.80)$.
3. Tangible results of the mentoring relationship (three items): examined the extent to which the mentor had facilitated material support, access to assistance, and provided protection to the household $($ alpha $=.68)$.

Scale scores ranged from 1-5, with higher scores reflecting positive youth perceptions and experiences concerning the mentor-youth relationship. Researchers investigated the relationship between these scale scores and frequency of mentor visits and found a significant association on all three scales. Those youth who reported being visited at least once a week had higher scores on all three scales (positive aspects of the relationship, adequacy of the time spent together, and tangible results) than those who reported less frequent mentor visits (see Figure 4).

\section{Other children living in the housebolds were minimally impacted by the mentorship pro- gram.}

A major goal of the mentor program was to improve the functioning of all members of the youth-headed household. As part of the survey, the youth heads of households were asked about how well the rest of the children were functioning in the home with regards to

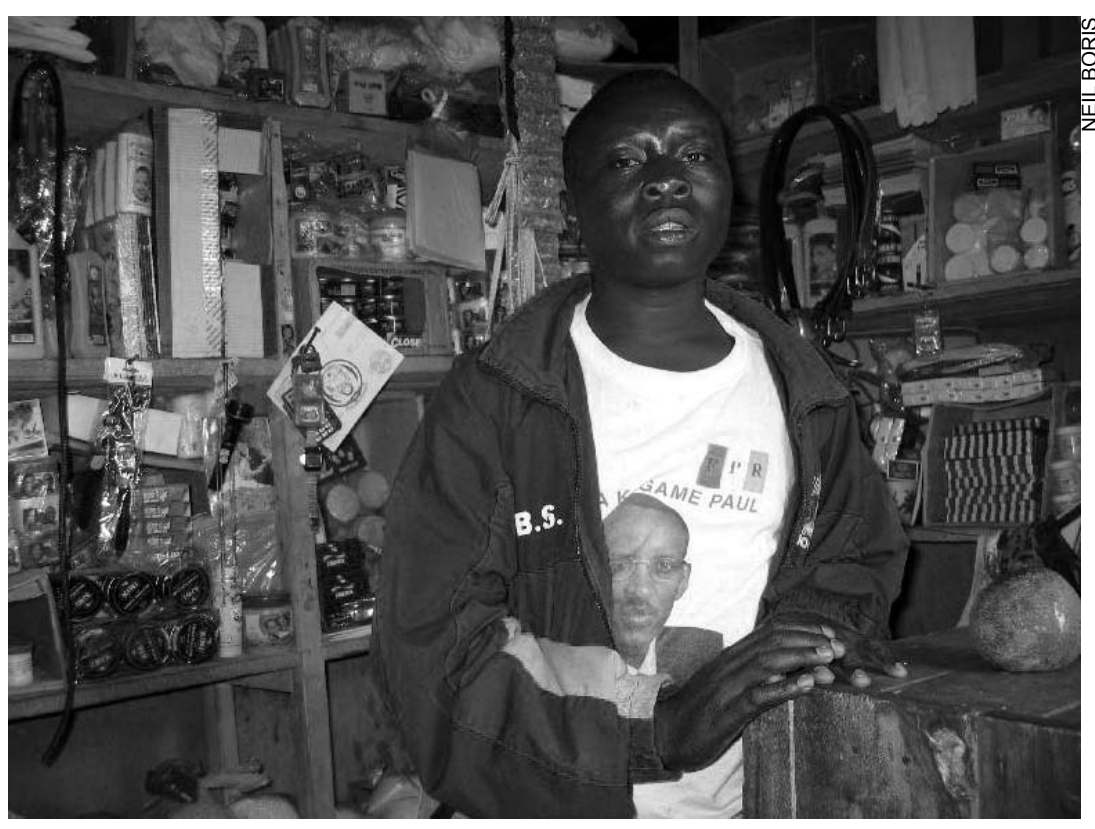

Phillipe, a 21-year-old head of household, in the store he rents to provide income for his three siblings. 
Figure 4 Relationship between frequency of mentor visits and youth scores on the mentor relationship scales

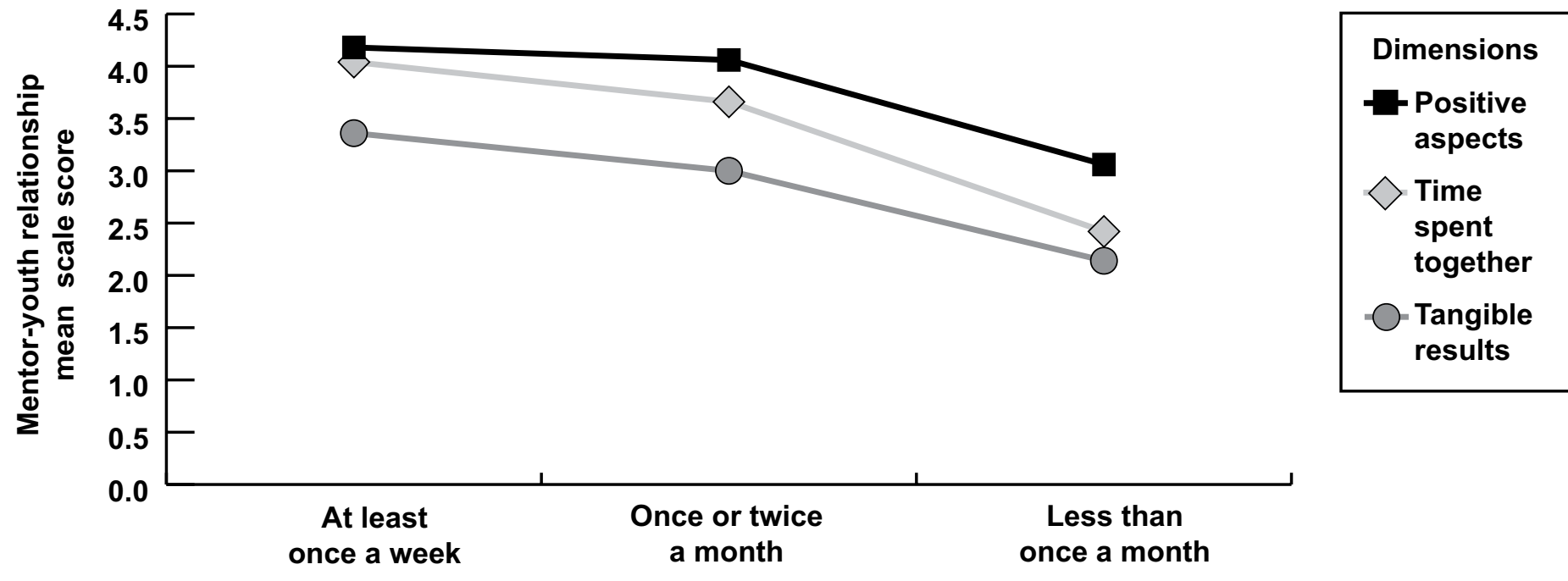

Frequency of mentor visits

their health status, school attendance, and behavioral indicators. Focus groups with the household heads also explored how the mentor program helped to enhance family functioning.

The youth-headed households varied substantially in their size and composition at baseline, and the researchers observed marked changes in composition at follow up. At baseline there were a total of 1,048 other household residents (siblings, other relatives, and children of the youth head of household) aged 18 and under. At follow up there was a marked decrease in the total number of household members (867 other residents). Among the other residents aged 18 and under, 11 percent were under five at baseline, while 14 percent were under age five at follow up; 32 percent were aged 6-12 at baseline and 31 percent at follow up; and 56 percent and 55 percent were aged 13-18 at baseline and follow up respectively.

The researchers found that there was no positive impact of the mentoring program on the health status of other children in the household. The health of children was most commonly rated by youth heads of household as fair or poor at both baseline and follow up. Among children aged six and over, there was reportedly a significant worsening in health status during the study period in both intervention and comparison areas.
There are some indications that the mentoring program had a positive impact on other variables among children and youth in the home. In the intervention areas, school attendance increased among teenagers (13-18) and refusal to go to school and to do chores decreased among 6-12 years olds; and there were no similar changes in the comparison group. These indicators may support the increased familial cooperation and improved parenting skills of the youth heads of household suggested in the focus groups.

Mentors were instrumental in resolving family conflicts, and identifying and addressing behavioral problems among the children and youth. For example, younger children in some households confided in mentors about problems with the youth who served as head of the household. In one instance, despite pleas from his younger siblings, a youth head continued to sell the seeds and manure provided by WVR, causing a great deal of conflict in the home. The mentor invested significant time and effort in dialogue and guidance with the youth to successfully resolve the problem. In another instance, a mentor intervened when a younger sibling confided that her older sister was sometimes physically abusive to her. The mentor helped establish a healthier relationship between the two by addressing the causes of sibling rivalry, discussing appropriate forms of discipline, and continually monitoring the situation. The trusting relationship 
and rapport that mentors established with the families helped facilitate discussion and resolution of sensitive issues.

Mentors were trained to work directly with the heads of households, thus the research team expected that even regular mentor visits would only indirectly impact the younger children living in the home, especially in just two years. Though there are few quantitative markers of change among children and youth, qualitative data highlight some positive changes that have resulted and the potential for others as a result of increased functioning of the family and improved parenting skills of the youth head of household.

They [mentors] taught us that we shouldn't be selfish and forget our young siblings. This helped because sometimes we used to take care of only ourselves and forget them.

Male, 18 years old

I never listened to the children I look after because I was always angry, but the mentor helps me. I now listen to them and solve their problems.

Male, 21 years old

\section{Conclusions}

Findings from this study suggest that mentoring from adults within the community can measurably mitigate adverse psychosocial outcomes among male and female youth who serve as heads of household. Despite disturbingly high levels of depression, maltreatment, and marginalization, and low levels of adult support reported at baseline, follow-up data over a relatively short time (18 months of intervention) indicate positive changes in these psychosocial outcomes among youth participating in the mentor program. Overall, the mentoring program appears to have enhanced social protection and community connectedness and minimized psychological problems among youth participants. In addition to providing immediate guidance, protection, and emotional support, consistent and regular access to a caring and stable adult may bolster resiliency and result in even more long term positive outcomes (Mastern and Coatsworth 1998).
The study has a few limitations that need to be acknowledged. The researchers aimed to initially follow up baseline survey respondents longitudinally and interview them again after two years; however this was not always possible due to changes in household formation associated with marriage and migration. Thus, the data were analyzed as two cross-sectional rounds. Since it was not possible to randomize under these circumstances, the differences observed could be influenced by other factors in the community that were not measured in the study. However, local advisers have noted no differences or other secular changes, other than the introduction of the mentoring program, which could account for the positive changes seen in the intervention communities.

This evaluation also makes clear that the psychosocial well-being of vulnerable youth is affected by a variety of stressors other than a lack of adult care and supervision. Respondents across both intervention and comparison communities reported harsh living conditions, such as not having enough food to eat, having few household assets, and being in poor health-all of which were associated with negative psychosocial outcomes. However, in spite of these stressors, the mentoring program demonstrated success in improving the psychosocial well-being of youth who serve as heads of households in southwestern Rwanda. The

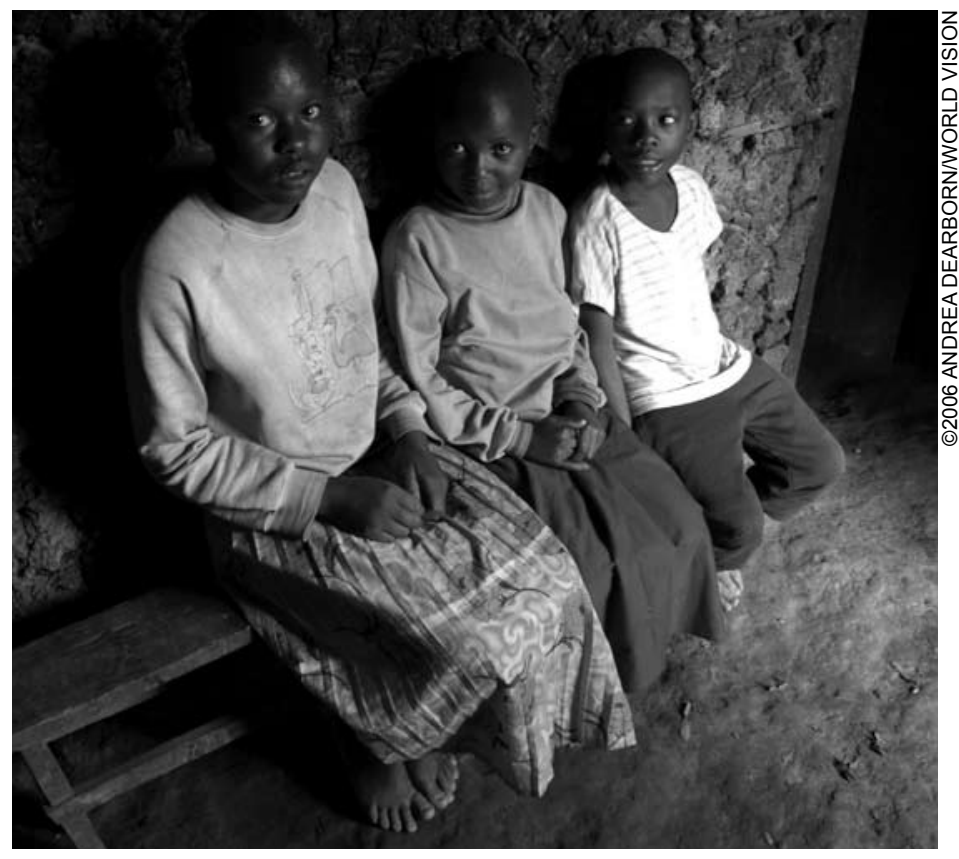

Leoncia, 14, with her younger sister, Everina, and younger brother, Domiciane, inside their home. 
following words of one youth participant convey how the program serves to help vulnerable youth cope with these strains and fosters positive growth and development:

Before, we had no hope for the future. After being advised we felt courageous. And today we feel that we will live, even if we will meet some problems, we will be able to solve them. This program helped us a lot.

Male, 17 years old

\section{Programmatic Implications}

\section{The mentorship program is a scaleable approach to improving psychosocial outcomes among vulnerable youth.}

Support to vulnerable youth was provided by community volunteers, with modest levels of investment. WVR provided training, regular monitoring, and supervision of mentors as well as incentives, public recognition, and emotional support. Small-scale support to a relatively small number of mentors resulted in impacts for a large number of youth.

\section{The mentorship approach increased commu- nity participation in the care of vulnerable youth.}

This program successfully engaged community adults in the care of vulnerable youth. Nearly half of youth reported being visited at least once a week, and many had a measurable reduction in their perceived marginalization. These markers suggest a mentoring program can serve as a catalyst for increasing community support to children in need.

\section{The frequency of mentor visits is important.}

These results emphasize the importance of frequent visits for developing a stable and caring relationship between mentors and youth. To foster positive rela- tionships, it is suggested that mentors visit households at least twice a month, if not weekly. Thus, to support this aim, programmers need to carefully consider the number of households assigned to each mentor as well as ease of transport and/or distance between the mentors and youth's homes.

\section{Females may need additional assistance to overcome depressive symptoms and reduce maltreatment.}

Gender was not a predictive factor in relation to marginalization or grief, suggesting that males and females are equally troubled by these issues. However, females were more susceptible to depressive symptoms and maltreatment. Therefore, programs should ensure specific protection measures for females and consider that females may need special assistance to prevent and overcome severe psychological problems.

\section{Programs need to be realistic about what aspects of psychosocial distress a mentoring program can alleviate.}

While the mentorship program did have a strong impact on youth perceptions of adult support, it may not be realistic for the program to have a strong impact on severe psychosocial outcomes such as depression, where more intensive clinical interventions may be necessary. Moreover, the association between having a parent killed in the genocide and the five outcomes assessed in this study suggests that children affected by traumatic loss may require more specialized attention. $\mathcal{X}$

November 2007 


\section{References}

Brown, L., T. R. Thurman, and L. Snider. 2005. "Strengthening the pyschosocial well-being of youthheaded households in Rwanda: Baseline findings from an intervention trial," Horizons Research Update. Washington, D.C.: Population Council.

Evans, R. 2005. "Social networks, migration and care in Tanzania: Caregivers' and children's resilience to coping with HIV/AIDS," Journal of Children and Poverty 11(2): 111-29.

Foster, G. et al. 1995. "Orphan prevalence and extended family care in a peri-urban community in Zimbabwe," AIDS Care 7(1): 3-17.

Rakita, S. 2003. "Lasting wounds: Consequences of genocide and war on Rwanda's children," Human Rights Watch (15)6.

Hunter, S. 2000. Reshaping Societies: HIVIAIDS and Social Change. New York: Hudson Run Press.

Masten, A. S., and J. D. Coatsworth. 1998. "The development of competence in favorable and unfavorable environments: Lessons from research on successful children," American Psychologist 53(2): 205-220.

Preble, E. 1990. "Impact of HIV/AIDS on children," Social Science and Medicine 6(31): 671-680.

Radloff, L. S. 1977. "The CES-D scale: A self-report depression scale for research in the general population," Applied Psychological Measurement 1: 385-401.

Snider, L. and A. Dawes. 2006. "Psychosocial vulnerability and resilience measures for national-level monitoring of orphans and other vulnerable children: Recommendations for the revision of the UNICEF psychological indicator," prepared for UNICEF.
UNICEF. 2006. "Africa's orphaned and vulnerable generations: Children affected by AIDS.” Geneva: UNICEF, UNAIDS, and PEPFAR.

\section{Acknowledgments}

The findings described in this report are part of a collaboration of three partners committed to improving the wellbeing of orphaned and vulnerable children and youth in Rwanda. The Tulane University School of Public Health (TSPH), Rwanda School of Public Health (RSPH) and World Vision Rwanda (WVR) formed this partnership in order to bring program implementers and researchers together to ensure quality psychosocial care and support through an adult mentorship program to youth-headed households. The intervention was generously funded by World Vision US, and the longitudinal operations research by the Horizons Program of the Population Council, with funding from United States Agency for International Development and the President's Emergency Plan for AIDS Relief.

Most importantly, we extend our respect and appreciation to the youth in Gikongoro, who gave freely of their time and shared sensitive and intimate information to open our eyes to the challenges and strengths of youth in difficult circumstances.

Suggested citation: Brown, Lisanne, Janet Rice, Neil Boris, Tonya Thurman, Leslie Snider, Joseph Ntaganira, Laetitia Nyirazinyoye, Edward Kalisa, and Emmanuel Nshizirungu. 2007. "Psychosocial benefits of a mentoring program for youth-headed households in Rwanda," Horizons Research Summary. Washington, DC: Population Council.

\section{Hprizons N}

Population Council/Horizons

Communications Unit

4301 Connecticut Avenue, NW

Suite 280

Washington, DC 20008

\section{P Population Council}

Tel: $202-237-9400$

Fax: 202-237-8410

horizons@popcouncil.org

www.popcouncil.org/horizons
This research summary is made possible by the generous support of the American people through the United States Agency for International Development (USAID) and the President's Emergency Plan for AIDS Relief under the terms of HRN-A-00-97-00012-00. The contents are the responsibility of the Horizons Program and do not necessarily reflect the views of USAID or the United States Government. 